INTERNATIONAL JOURNAL OF ORGANIZATION THEORY AND BEHAVIOR, 20 (4), 519-543 WINTER 2017

\title{
GOAL INTERDEPENDENCE, SUBGROUP FORMATION, AND CONFLICT IN TEAMS
}

\author{
(Rae) Yunzi Tan*
}

\begin{abstract}
This research investigates subgroup formation as an important mediator in the goal interdependence-intragroup conflict linkage. Specifically, it proposes that subgroup formation will mediate the relationship between cooperative goal interdependence and intragroup conflict, but not for competitive goal interdependence and intragroup conflict. Further, competitive goal interdependence is posited to have direct, positive effects on intragroup conflict. Using structural equation modeling analyses with 79 student project teams, the findings revealed that subgroup formation fully mediated the relationship between cooperative goal interdependence and task and process conflict, but only partially mediated the relationship between cooperative goal interdependence and relationship conflict. As predicted, subgroup formation did not mediate the relationship between competitive goal interdependence and intragroup conflict; however, competitive goal interdependence was negatively, rather than positively, related to intragroup conflict.
\end{abstract}

\section{INTRODUCTION}

Work groups or teams are prevalent and indispensable in most organizations today (Cohen \& Bailey, 1997; Mathieu et al., 2008). In order for organizational teams to function effectively and to yield productive outcomes, it is imperative for them to manage their intragroup conflicts, i.e., internal disagreements, tensions or perceived incompatibilities regarding tasks (task conflict), interpersonal relations (relationship conflict) or task-related

* (Rae) Yunzi Tan, Ph.D., is Assistant professor, School of Public and International Affairs, University of Baltimore. Her research and teaching interests include conflict dynamics in work groups and teams, diversity training, workplace aggression, and organizational change and development.

Copyright $\odot 2017$ by PrAcademics Press 
procedures (process conflict) among team members (Jehn, 1994, 1995, 1997), constructively. Past studies (for meta-analyses, see De Dreu \& Weingart, 2003; de Wit, Greer \& Jehn, 2012) have demonstrated that intragroup conflict can exert significant influence on team functioning (e.g., Griffith, Connelly \& Thiel, 2014; Puck \& Pregernig, 2014; Rispens et al., 2011) and team effectiveness (e.g., Shaw, Zhu, Daffy et al., 2011; Tekleab, Quigley \& Tesluk, 2009).

A considerable amount of research has also examined various factors contributing or relating to intragroup conflict (for reviews, see Jehn \& Bendersky, 2003; Jehn, Greer \& Rupert, 2008), including goal interdependence. Goal interdependence refers to how team members perceive their goals to be structured or are related to one another (Deutsch, 1949, 1973; Johnson \& Johnson, 2005; Tjosvold, 1986), and constitutes an important contextual characteristic of teams. Indeed, organizational researchers have emphasized the need for more research on interdependence in teams (Kozlowski \& Bell, 2003; Mathieu et al., 2008). Prior studies have shown that goal interdependence directly affects the level and nature of intragroup conflict (e.g., Chen, Tjosvold \& Wu, 2008; Medina, Lunduate \& Guerra, 2008). An experimental study conducted by Chen, Tjosvold and Wu (2008), for instance, reported that cooperative goals, relative to competitive and independent goals, resulted in less perceived task and relationship conflict between employees and their managers in China. Medina and colleagues (2008), in a field study with 401 Spanish participants, found that goal interdependence was negatively associated with both task and relationship conflict; they also found that goal interdependence interacted with position power to influence intragroup conflict - participants perceived less task and relationship conflict under conditions of low position power and cooperative goal interdependence.

Despite these conclusions about the relationship between goal interdependence and intragroup conflict, much less is known about the mechanisms underlying this relationship. How does the interrelatedness of team members' goals affect their perceptions of conflict within the team? Why do cooperative goals discourage intragroup conflict, while competitive goals exacerbate them? To address these questions, I draw upon relevant research and theories from the group diversity and faultlines literatures to propose that perceived subgroup formation, which refers to the extent to which 
members perceive subgroups or cliques within the team (Jehn \& Bezrukova, 2010), may serve as one important mechanism in explaining the relationship between goal interdependence and intragroup conflict. Specifically, I reason that subgroup formation will act as a conduit through which cooperative, but not competitive, goal interdependence affects intragroup conflict outcomes, i.e., task, relationship and process conflict. The purpose of this paper, then, is to test a hypothesized mediation model of subgroup formation on (cooperative) goal interdependence and intragroup conflict (see Figure 1).

FIGURE 1

Hypothesized Model: Proposed Relationships among Goal Interdependence, Subgroup Formation and Intragroup Conflict

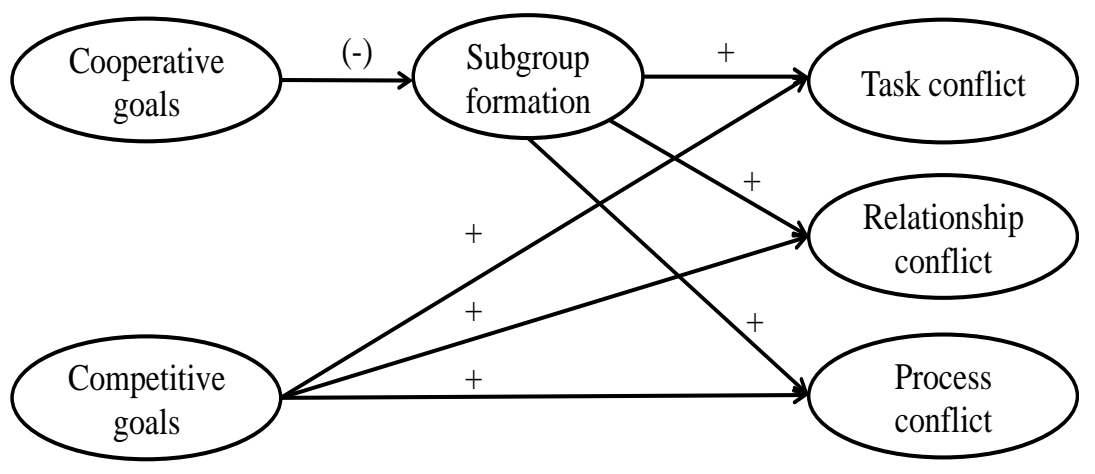

By examining the proposed linkages among goal interdependence, subgroup formation and intragroup conflict, this research contributes to the current literature in several ways. It is one of few, if not the first, studies to focus on intervening variables between goal interdependence and conflict in teams. Past research has largely looked at the interactive effects of goal interdependence and contextual or moderator variables, such as relationship values (Chen, Tjosvold \& Wu, 2008) and power bases (Medina, Lunduate \& Guerra, 2008) on intragroup conflict. Further, this study broadens our understanding of cooperative and competitive goal interdependence by demonstrating how these concepts may operate using different pathways to influence critical group processes, such as intragroup conflict. This research also addresses recent calls for future 
investigations that examine factors or mechanisms contributing to perceived subgroup formation (e.g., Zellmer-Bruhn et al., 2008) in teams.

In the next section, the author will briefly review relevant literature pertaining to the focal constructs of interest, namely goal interdependence and perceived subgroup formation in teams, and then present the arguments leading to the hypotheses examined in this research.

\section{Goal Interdependence}

Goal interdependence, as defined in this study, is based upon Deutsch's $(1949,1973)$ theory of cooperation and competition. In this theory, Deutsch reasoned that goal interdependence is likely to occur in one of three forms: cooperative, competitive and independent. Cooperative goal interdependence (or cooperative goals) describes a situation in which two or more group members perceive their goals as positively linked to one another. Put simply, in order for one member to achieve his or her goal, other members have to achieve their goals as well. This is similar to a "swim-swim/sinksink" scenario: if one swims, the other swims; conversely, if one sinks, the other sinks. Competitive goal interdependence (or competitive goals), on the other hand, concerns a situation in which two or more group members perceive their goals as negatively linked to one another. In other words, for one member to achieve his or her goals, other members will have to fail to achieve their goals. This is akin to a "swim-sink" scenario: if one swims, the other sinks, or vice versa. Finally, as for independent goal interdependence (or independent goals), this describes a situation whereby group members' goals are unrelated to one another. How and whether one group member achieves his or her goal has no bearing on that of other group members. In this case, other group members are unaffected by whether one group member swims or sinks.

Since Deutsch's $(1949,1973)$ theorizing, much empirical work has accumulated to test his concepts of goal interdependence across various settings (Johnson, 2003; Johnson \& Johnson 2005; Johnson et al., 1981). To date, a considerable body of research exists about the nature, antecedents, and consequences of goal interdependence in organizational contexts (Tjosvold, 1998, 2008). For example, cooperative goals in the workplace have been found to improve 
employees' levels of affective attitudes (Lu \& Tjosvold, 2013), psychological safety (Chen \& Tjosvold, 2012), organizational citizenship behaviors (Wong, Tjosvold \& Liu, 2009), and open-minded discussions (Tjosvold, 2002). On the contrary, competitive goals, relative to cooperative goals, have generally been associated with more negative effects for individuals and groups at work: increased quit intentions (Lu \& Tjosvold, 2013), less organizational citizenship behaviors (Wong, Tjosvold \& Liu, 2009), lower quality leader-member relationships (Chen \& Tjosvold, 2008), and less effective decisionmaking (Chen, Tjosvold \& Wu, 2008). As for independent goals, past research has noted that group members often perceive competitive and independent goals simultaneously (Tjosvold \& Yu, 2004; Tjosvold, Yu \& Hui, 2004). Further, independent goals generally yielded similar, negative effects (to a lesser extent, though) on various outcomes as those of competitive goals (e.g., Chen, Lu, Tjosvold \& Lin, 2008; Lu \& Tjosvold, 2013; Tjosvold, Peng, Chen \& Su, 2008; Wong, Tjosvold \& Liu, 2009). Given such relatively similar effects of independent goals to those of competitive goals found in past research, this study thus focuses only on cooperative and competitive goals.

In light of the aforementioned research, it is clear that goal interdependence plays a critical role in team functioning and effectiveness. Further, it exerts significant influence on group process variables, such as intragroup conflict, that can facilitate or undermine the productivity and maintenance of teams (e.g., Chen, Tjosvold, \& Wu, 2008; Tjosvold, Tang \& West, 2004; Tjosvold, Wong, Nibbler \& Pounder, 2002; Tjosvold \& Yu, 2004). What is less clear in current research, however, are the underlying mechanisms that link goal interdependence to group processes, specifically intragroup conflict. Here, the author proposes subgroup formation as a possible intervening mechanism that may help explain the linkage between goal interdependence and conflict in teams.

\section{Subgroup Formation}

Perceived subgroup formation occurs when individuals view the presence of smaller collectives within a larger group, on the basis of one or more perceived similar or shared characteristics (Cronin et al., 2011; Zellmer-Bruhn et al., 2008). Recent studies on perceptions of subgroup formation have shown that it can exert significant effects on team processes and outcomes, such as member satisfaction and 
team effectiveness respectively (e.g., Cronin et al., 2011; Homan \& Greer, 2007; Jehn \& Bezrukova, 2010; Zellmer-Bruhn et al., 2008). Research has also examined factors that can affect subgroup perceptions within groups, e.g., cognitive and affective integration (Cronin et al., 2011) and perceived work style similarity (ZellmerBruhn et al., 2008).

\section{Subgroup Formation and Cooperative Goal Interdependence}

For this study, I propose that perceived subgroup formation is likely to act as a mediating mechanism through which cooperative goal interdependence affects intragroup conflict. Based on the information-elaboration/decision-making perspectives from the group diversity and faultlines literatures (for a review, see van Knippenberg \& Schippers, 2007), group members who perceive cooperative goals among them are likely to be motivated to share task-relevant information and perspectives with one another in order to facilitate success of their mutual goal attainment (e.g., Chen, Tjosvold \& Wu, 2008; Chen, Tjosvold, Huang \& Xu, 2011). Such information exchange and elaboration would, in turn, lead to greater awareness about unique, task-related perspectives, viewpoints, and preferences among members. Applying the attraction-similarity paradigm (Bryne, 1971), the heightened understanding of members' unique and taskrelated perspectives, ideas and attitudes may also lead team members to interact or identify more with some members who are seen as having similar viewpoints, perspectives or attitudes, relatively to others in the same team. Consequently, such perceptions of subgroups or smaller coalitions, based on members' perceived similarity in ideas, attitudes or viewpoints, may emerge among members in the broader team (e.g., Eisenhardt \& Bourgeois, 1988; Murnighan \& Brass, 1991).

With the occurrence of perceived subgroups, in-group/out-group distinctions (Brewer, 1999; Tajfel \& Turner, 1986) are activated along subgroup lines, and members may come to reduce cross-subgroup interactions and to increase communications within subgroup boundaries instead (e.g., Polzer, Mannix \& Neale, 1998). Consistent with past research (e.g., Jehn \& Bezrukova, 2010), members who perceive subgroups in their teams would also likely experience more disagreements or tensions over tasks, personal differences, and taskrelated processes within the entire team. Given the above reasoning, it is therefore hypothesized that: 
H1a: Subgroup formation will mediate the relationship between cooperative goals and task conflict, such that cooperative goals will be negatively related to subgroup formation, which will, in turn, be positively related to task conflict.

H1b: Subgroup formation will mediate the relationship between cooperative goals and relationship conflict, such that cooperative goals will be negatively related to subgroup formation, which will, in turn, be positively related to relationship conflict.

H1c: Subgroup formation will mediate the relationship between cooperative goals and process conflict, such that cooperative goals will be negatively related to subgroup formation, which will, in turn, be positively related to process conflict.

\section{Subgroup Formation and Competitive Goal Interdependence}

By contrast, it is posited that perceived subgroup formation will be unlikely to have a mediating effect on the relationship between competitive goal interdependence and intragroup conflict. When members perceive their goals as conflicting or opposing to those for others in the team, they tend to decrease information sharing and limit open-minded discussions with one another (e.g., Chen, Lu, Tjosvold \& Lin, 2008; Tjosvold, 1990), and may become motivated to seek alternative ways or options to accomplish their own goals. With a win-lose mentality associated with competitive goal structures, people are likely to be less concerned with forming coalitions with fellow team members or to be aware of any existing or emerging subgroups within the team, thus lowering the occurrence or salience of subgroup formation. Rather, members who view their own goals as competitively linked may take active steps or intentionally engage in attempts to hinder the attainment of fellow team members' goals (Deutsch, 1973; Johnson et al., 1981). As such, teams whose members perceive competitive goals with one another are also likely to experience higher levels of intragroup conflict (Chen, Tjosvold \& $\mathrm{Wu}, 2008)$.

H2a: Subgroup formation will not mediate the relationship between competitive goals and task conflict; instead, competitive goals will be directly and positively related to task conflict. 
$\mathrm{H} 2 \mathrm{~b}$ : Subgroup formation will not mediate the relationship between competitive goals and relationship conflict; instead, competitive goals will be directly and positively related to relationship conflict.

H2c: Subgroup formation will not mediate the relationship between competitive goals and process conflict; instead, competitive goals will be directly and positively related to process conflict.

\section{METHOD}

\section{Participants and Procedures}

Seventy nine undergraduate student project teams ( $n=417$ students) from various sections of a core business administration course at a university in the Asia-Pacific region participated voluntarily in this cross-sectional field study. Prior to data collection, the study protocols were reviewed and approved by the Institutional Review Board (IRB) at the university. The participants were between 17 and 27 years old $(M=21.7, S D=1.65) .54 \%$ of them were identified as female ( $n=179), 45 \%$ as male $(n=151)$, and the remaining $1 \%$ as 'other,' e.g., transgender $(n=2)$.

The students worked in the same teams throughout the academic semester, and all teams were required to complete a final project that was consistent across all course sections at the end of the semester. The student project teams consisted of three to eight members each $(M=4, S D=1.09) .57(72 \%)$ of the teams sampled were assigned by the instructors, while the remaining $22(28 \%)$ teams were selforganized among the students. A means comparison test was conducted to assess whether significant group differences existed among the teams based on the type of group assignment (assigned vs. self-sorted), and the results revealed no significant differences among the teams based on group assignment.

Data were collected from individual project team members using an online questionnaire at the end of the semester. Participants were provided with either extra course credit or a small monetary compensation for taking part in this study. Participants were also ensured anonymity and confidentiality of their information to encourage candid and honest responses as they complete the questionnaires. 


\section{Study Measures}

\section{Goal Interdependence}

I adapted items from Lu, Tjosvold and Shi's (2010) measure to assess individual perceptions of cooperative and competitive goal interdependence. Participants rated items using a five-point Likert scale ( $1=$ strongly disagree to $5=$ strongly agree). This measure consisted of two sub-scales: positive goal interdependence and negative goal interdependence. A sample item from the five-item positive goal interdependence sub-scale: "In this team, members want each other to succeed"; Cronbach's alpha $=.67$ ). One sample item from the five-item negative goal interdependence sub-scale: "In this team, members like to show that they are superior to each other (reverse-coded)"; Cronbach's alpha $=.70$ ).

\section{Subgroup Formation}

Adapted items from Cronin, Bezrukova, Weingart, et al.'s (2011) scale were used to assess members' perceptions of subgroup formation in teams. Sample items from this measure included the following: "To what extent has your team split into subgroups?" and "To what extent has your team split into multiple or smaller cliques?" (Cronbach's alpha $=.80$ ). The items were scored on a five-point Likert scale $(1=$ not at all or to a very small extent; $5=$ to a very large extent).

\section{Intragroup Conflict}

To assess participants' ratings of perceived conflict within their teams, I used Jehn and Mannix's (2001) scale to measure the three types of intragroup conflicts: task, relationship and process conflicts. The nine-item scale comprised three sub-scales to assess each of the intragroup conflict type. Each sub-scale also consisted of three items. Sample items for each of the three sub-scales respectively were: "How much conflict of ideas is there in this team?" "How much relationship tension is there in this team?" and "How often are there disagreements about who should do what in this team?" The Cronbach's alphas were .80 (task conflict sub-scale), .86 (relationship conflict sub-scale), .79 (process conflict sub-scale), and .88 (overall intragroup conflict scale). All items for this measure are rated on a five-point scale $(1=$ "never/not at all or to a very small extent"; $5=$ "always/to a very large extent"). 


\section{ANALYSIS}

\section{Data Aggregation}

Since this study was concerned with team-level constructs, sufficient levels of within-team agreement and between-team variability were needed in order to justify data aggregation for the study variables. To do so, I calculated the within-group interrater agreement indices or $r_{w g s}$ (James, Demaree, \& Wolf, 1984, 1993) and intraclass correlations (Bliese, 2000) using the aggregated team-level data for each measure. The $r_{w g}$ measures the degree to which individual ratings within a group are interchangeable, and values of $r_{w g s}$ that are greater or equal to .70 are considered good indicators of sufficient within-team agreement (George \& Bettenhausen, 1990). As for intraclass correlations, these are measured in two forms: ICC (1), which assesses the extent to which variability in individual ratings is explained by group membership, and ICC (2), which is concerned with estimating the reliability of group means. ICC (I) values of .12 or higher and ICC (2) values of .70 or higher would indicate sufficient support for within-team agreement and between-team variability respectively (Bliese, 2000).

Table 1 shows the data aggregation indices for all the team-level measures. The median $r_{\text {wgs }}$ for all measures were .70 or greater, thus

TABLE 1

Data Aggregation Indices for All Team-Level Measures $(\mathrm{N}=79)$

\begin{tabular}{|l|c|c|c|}
\hline \multicolumn{1}{|c|}{ Variable } & Median $r_{W G}(J)$ & ICC (1) & ICC (2) \\
\hline 1. Goal interdependence & .96 & .17 & .68 \\
\hline Cooperative & .95 & .40 & .77 \\
\hline Competitive & .89 & .16 & .49 \\
\hline 2. Subgroup formation & .80 & .45 & .76 \\
\hline 3. Intragroup conflict & .96 & .31 & .80 \\
\hline Task conflict & .96 & .56 & .80 \\
\hline Relationship conflict & .96 & .73 & .89 \\
\hline Process conflict & .96 & .60 & .82 \\
\hline
\end{tabular}

Note. ICC (1) = intra-class correlation for individual ratings based on a one-way random effects ANOVA. ICC (2) = intra-class correlation for team mean ratings based on a one-way random effects ANOVA. 
indicating acceptable levels of within-team agreement. The ICC (1) values for all the measures also met the recommended value of .12 or higher. The ICC (2) values for all measures were also .70 or greater, except for competitive goal interdependence (.49) and overall goal interdependence (.68). Nonetheless, since the other data aggregation indices, i.e., $r_{w g}$ and ICC (1) values, for all the team measures were acceptable, it was justified to aggregate the data for all variables to the team level.

\section{Scale Validation}

The author conducted a series of confirmatory factor analyses (CFAs) using Mplus 7.3 (Muthén \& Muthén, 1998-2012) to examine whether the participants' ratings would load onto six distinct factors, namely, cooperative goals, competitive goals, subgroup formation, task conflict, relationship conflict, and process conflict. Specifically, the author compared the proposed six-factor model to two alternative models: a three-factor model and a one-factor model. The three-factor model was selected as an alternative solution as it might be possible that the subscales for goal interdependence (cooperative and competitive) and for intragroup conflict (task, relationship and process) may not be empirically distinct. The CFAs were conducted using the individual ratings from 410 participants.

Results (see Table 2) indicate that the proposed six-factor model fits the data best, relative to the other two alternative models, with $\mathrm{CFI}=.94$, RMSEA $=.05$, SRMR $=.04$. The chi-squares of both the three-factor and one-factor models were significantly greater than that of the six-factor model solution. As such, it is reasonable to conclude that there are six distinct factors measured in this study.

TABLE 2

Confirmatory Factor Analyses $(\mathrm{N}=410)$

\begin{tabular}{|l|c|c|c|c|c|c|c|}
\hline & d.f. & Model $\chi^{2}$ & $\Delta \chi^{2}$ & $\Delta$ d.f. & RMSEA & CFI & SRMR \\
\hline Baseline 6-factor model & 215 & $430.87 * *$ & & & .05 & .94 & .04 \\
\hline 3-factor modela & 227 & $769.72 * *$ & 338.85 & 12 & .08 & .85 & .06 \\
\hline 1-factor model & 230 & $1329.23 * *$ & 559.51 & 3 & .11 & .70 & .08 \\
\hline
\end{tabular}

Note. a M2 combines cooperative and competitive goals into one factor (goal interdependence), and combines task, process and relationship conflict into another factor (group conflict). $* * p<.01$. 


\section{Hypotheses Testing}

Zero-order correlational analyses were used to provide initial tests of the study hypotheses. Structural equation modeling analyses were then applied to assess the underlying covariance structure of the relationships among cooperative goal interdependence, competitive goal interdependence, subgroup formation, task conflict, relationship conflict, and process conflict in the hypothesized model. As past research has demonstrated, structural equation modeling is an appropriate and preferred analytical tool to use in this research, as it is a powerful and sophisticated technique that enables researchers to specify and test complex "path" or mediation models, particularly in examining predictive relationships among constructs.

Since it is unclear from the existing literature whether subgroup formation would partially or fully mediate the relationship between cooperative and/or competitive goal interdependence and intragroup conflict, I conducted a nested model test by comparing three alternative models to the proposed model $\left(\mathrm{M}_{2}\right)$ : The three alternative models were a non-mediation model $\left(\mathrm{M}_{1}\right)$ and two partial mediation models $\left(M_{3}\right.$ and $\left.M_{4}\right)$. Specifically, $M_{1}$ posits an indirect-effects model whereby subgroup formation fully mediates the relationship between both types of goal interdependence and all three intragroup conflict types. The first partial mediation model, $\mathrm{M}_{3}$, proposes that subgroup formation fully mediates the relationship between cooperative goal interdependence and task/process conflict but partially mediates the relationship between cooperative goal interdependence and relationship conflict, and that competitive goals are directly linked to all three intragroup conflict types. The second partial mediation model, $\mathrm{M}_{4}$, proposes that subgroup formation partially mediates the relationship between cooperative goals interdependence and all three intragroup conflict types, and that competitive goals are directly linked to all three intragroup conflict types.

In terms of sample size considerations, it should be noted that while the sample of teams $(n=79)$ examined in this study would be considered relatively small, it would still be within acceptable levels based on known guidelines, e.g., 10 cases for each variable (Nunnally, 1967) and 5 or 10 observations for each estimated parameter (Bentler \& Chou, 1987; Bollen, 1989), in the literature involving SEM analyses. 


\section{RESULTS}

\section{Correlational Findings}

Table 3 reports the means, standard deviations, group reliability scores based on the teams' means (Snijders \& Bosker, 1999, p. 26), and zero-order correlations among the study variables. Findings from the correlational analyses indicate preliminary support for Hypotheses 1a-c: cooperative goal interdependence is negatively associated with subgroup formation ( $r=-.46, p<.01$ ), and subgroup formation is, in turn, positively associated with all three intragroup conflict types: task $(r=.42, p<.01)$, relationship $(r=.52, p<.01)$ and process conflict $(r=.51, p<.01)$. By contrast, the correlation results did not offer preliminary support for Hypothesis 2a-c: competitive goal interdependence was negatively related, rather than unrelated, to subgroup formation $(r=-.32, p<.01)$; competitive goal interdependence was also negatively, rather than positively, related to task conflict $(r=-.41, p<.01)$, relationship conflict $(r=-.58, p<$ $.01)$, and process conflict $(r=-.44, p<.01)$.

TABLE 3

Means, Standard Deviations, and Correlations among Study Variables (Team Level, $\mathrm{N}=79$ )

\begin{tabular}{|l|l|l|l|l|l|l|l|l|}
\hline Variable & $\mathrm{M}$ & $\mathrm{SD}$ & 1 & 2 & 3 & 4 & 5 & 6 \\
\hline $\begin{array}{l}\text { 1. Cooperative goal } \\
\text { interdependence }\end{array}$ & 19.68 & 1.47 & $(.78)$ & & & & & \\
\hline $\begin{array}{l}\text { 2. Competitive goal } \\
\text { interdependence }\end{array}$ & 17.84 & 1.65 & $.49 * *$ & $(.73)$ & & & & \\
\hline 3. Subgroup formation & 7.67 & 1.92 & $-.46 * *$ & $-.32^{* *}$ & $(.82)$ & & & \\
\hline 4. Task conflict & 7.35 & 1.38 & $-.35^{* *}$ & $-.41^{* *}$ & $.42^{* *}$ & $(.86)$ & & \\
\hline 5. Relationship conflict & 4.99 & 1.53 & $-.58^{* *}$ & $-.58^{* *}$ & $.52^{* *}$ & $.69^{* *}$ & $(.92)$ & \\
\hline 6. Process conflict & 5.25 & 1.25 & $-.37 * *$ & $-.44^{* *}$ & $.51^{* *}$ & $.45^{* *}$ & $.61^{* *}$ & $(.83)$ \\
\hline
\end{tabular}

Notes. Numbers in parentheses are team-level reliability coefficients for the measures. $* * p<.01$.

\section{Structural Equation Findings}

Structural equation analyses through Mplus 7.3 were used to test the hypothesized model by exploring the underlying relationships among the six study variables. Table 4 reports the fit indices for the hypothesized model $\left(M_{2}\right)$ as compared to those for the three alternative models $\left(M_{1}, M_{3}\right.$ and $\left.M_{4}\right)$. The hypothesized model, $M_{2}$, provided a significantly better fit to data $\left(X^{2}=11.07, d f=4, p<.05\right)$ 
compared to $M_{1}$, the non-mediation model $\left(x^{2}=35.64, d f=6, p<\right.$. $01)$. The $X^{2}$ difference between $M_{1}$ and $M_{2}$ was also significant $\left(\Delta x^{2}\right.$ $(2)=24.57, p<.01$ ), indicating that the omission of direct links between competitive goals and intragroup conflict and the inclusion of a direct link between competitive goals and subgroup formation significantly deteriorated the hypothesized model.

When the two partial mediation models, $M_{3}$ and $M_{4}$, were tested against the hypothesized model, $M_{2}$, both $M_{3}$ and $M_{4}$ showed significant decreases in the model $X^{2}\left(\mathrm{M}_{3} \Delta \mathrm{X}^{2}(1)=9.36, p<.01\right.$; $M_{4} \Delta X^{2}(3)=9.87, p<.01$ ), thus suggesting that the addition of direct links between cooperative goals and intragroup conflict significantly improved model fit to data. Based on the parsimony principle, $\mathrm{M}_{3}$ also provided a slightly better fit to data compared to $M_{4}$, given the former's more favorable RMSEA and TLI/NNFI values (see Table 4).

TABLE 4

Fit Statistics for the Structural Equation Modeling Analyses

\begin{tabular}{|c|c|c|c|c|c|c|c|}
\hline & $\frac{4}{6}$ & $\begin{array}{l}\bar{\Phi} \\
\frac{0}{2} \tilde{x}\end{array}$ & 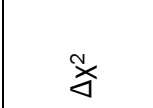 & 戸吕 & 蒠 & 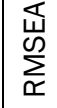 & 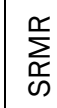 \\
\hline Null model $\left(\mathrm{M}_{0}\right)$ & 14 & $175.25 * *$ & & & & & \\
\hline $\begin{array}{l}\text { Non-mediation model }\left(\mathrm{M}_{1}\right) \text { : } \\
\text { Cooperative/competitive goals } \\
\text { have direct links to subgroup } \\
\text { formation; subgroup formation } \\
\text { has direct links to all three } \\
\text { intragroup conflict types }\end{array}$ & 6 & $35.64 * *$ & $139.61 * *$ & .57 & .82 & .25 & .14 \\
\hline $\begin{array}{l}\text { Hypothesized model }\left(\mathrm{M}_{2}\right) \text { : } \\
\mathrm{M}_{1} \text {, with deleted link from } \\
\text { competitive goals to subgroup } \\
\text { formation, and added links from } \\
\text { competitive goals to all three } \\
\text { intragroup conflict types }\end{array}$ & 4 & $11.07 *$ & $24.57 * *$ & .85 & .96 & .15 & .05 \\
\hline $\begin{array}{l}\text { Partial mediation model }\left(\mathrm{M}_{3}\right) \text { : } \\
\mathrm{M}_{2} \text {, with added link from coope- } \\
\text { rative goals to relationship } \\
\text { conflict }\end{array}$ & 3 & $1.71, n s$ & $9.36 * *$ & 1.04 & 1.00 & 0 & .03 \\
\hline $\begin{array}{l}\text { Partial mediation model }\left(\mathrm{M}_{4}\right) \text { : } \\
\mathrm{M}_{3}, \text { with added links from } \\
\text { cooperative goals to task and } \\
\text { process conflict }\end{array}$ & 1 & $1.20, n s$ & $9.87 * *$ & .98 & 1.00 & .05 & .03 \\
\hline
\end{tabular}

Notes. * $p<.05, * * p<.01$. 
$\mathrm{M}_{3}$, which adds a direct link between cooperative goals and relationship conflict to the hypothesized model, $\mathrm{M}_{2}$, was therefore accepted as the final model in the model comparison analyses.

Path estimates for the final partial mediation model, i.e., $\mathrm{M}_{3}$, are depicted in Figure 2. In support of Hypotheses 1a-c, cooperative goal interdependence has a negative effect on subgroup formation ( $\beta=$ $.60, p<.01)$, and subgroup formation has positive effects on task conflict ( $\beta=.24, p<.01)$, relationship conflict $(\beta=.23, p<.01)$, and process conflict $(\beta=.27, p<.01)$. Cooperative goal interdependence also has a direct negative effect on relationship conflict $(\beta=-.25, p<$ .05).

Hypotheses 2a-c, on the other hand, were partially supported; further, significant opposite findings were observed. Subgroup formation is unrelated to competitive goal interdependence $(\beta=.15$, n.s.), and competitive goal interdependence is found to exert negative, rather than positive, effects on task conflict $(\beta=-.25, p<$ $.01)$, relationship conflict $(\beta=-.35, p<.01)$, and process conflict $(\beta=$ $-.23, p<.01)$.

FIGURE 2

Final Model: Path Coefficients among Goal Interdependence, Subgroup Formation, and Intragroup Conflict

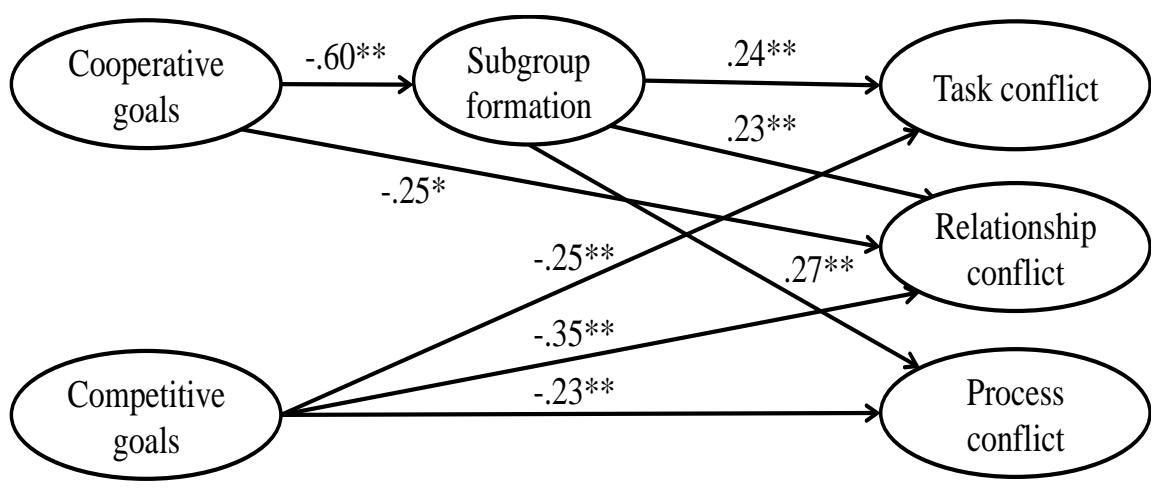

Notes. $* p<.05 ; * * p<.01$ 


\section{DISCUSSION}

While considerable research has been conducted on goal interdependence and intragroup conflict in teams, much less attention has been directed at investigating the mechanisms through which cooperative and competitive goal interdependence affect intragroup conflict. This study proposes that perceived subgroup formation serves as an important intervening variable in the goal interdependence-intragroup conflict linkage, particularly as it relates to cooperative goal interdependence; on the other hand, subgroup formation is posited to have no mediating effect between competitive goal interdependence and intragroup conflict.

As such, the main goal of this study was to examine whether perceived subgroup formation acts as an intervening mechanism between cooperative, and not competitive, goal interdependence and various forms of intragroup conflict, i.e., task, relationship and process conflict. The study's findings provided support for this hypothesized relationship: Subgroup formation fully mediated the relationship between cooperative goals and task and process conflict, and partially mediated the relationship between cooperative goals and relationship conflict. On the other hand, subgroup formation did not mediate the relationship between competitive goals and all three forms of intragroup conflict. However, contrary to prior research, competitive goals were also found to have direct negative, rather than positive, effects on all three intragroup conflict types.

By demonstrating that subgroup formation acts as a mediator between cooperative goal interdependence and intragroup conflict, but not between competitive goal interdependence and intragroup conflict, this research suggests that the two goal interdependence types do not affect important team processes, such as intragroup conflict, through identical or similar mechanisms or pathways. In other words, the findings convey the importance of "uncoupling" cooperative and competitive goal interdependence in future investigations so we can better understand how they may impact critical team processes or outcomes differently. More research is needed to identify and examine other mechanisms through which cooperative and competitive goals influence intragroup conflict differently.

Findings from this study also indicate that the mediating effects of subgroup formation between cooperative goal interdependence 
and intragroup conflict varied, depending on the type of intragroup conflict involved. Specifically, members' perceptions of subgroup formation in their teams fully drive the impact of their perceptions of cooperative goal interdependence with one another on the conflicts they experienced, as these relate to the tasks involved (task conflict) or to how the tasks are handled (process conflict); members' perceptions of subgroup formation, however, only, account for part of the relationship between their perceived cooperative goal interdependence and perceived conflicts that are based on interpersonal relations or personal differences (relationship conflict). These results suggest that the relationship between cooperative goal interdependence and relationship conflict is relatively more complex, and that perceived cooperative goal interdependence itself can mitigate conflict based on interpersonal differences or relational tensions.

Another interesting conclusion drawn from this research concerns the unexpected direction of the relationship between competitive goals and intragroup conflict. In this study, members' perceptions of competitive goals with one another led to lower, rather than higher levels of perceived task, relationship and process conflict in their teams. This finding contradicts prior research that has generally reported positive associations between competitive goals and intragroup conflict (e.g., Chen, Tjosvold \& Wu, 2008; Medina, Lunduate \& Guerra, 2008). One possible explanation for this finding could be that team members may have perceived competitive and independent goals with one another at the same time (Tjosvold \& Yu, 2004; Tjosvold, Yu \& Hui, 2004). Consequently, they may have engaged in more independent activities or have sought out resources outside the team to accomplish their goals. Such behaviors or activities would then have limited the amount of communication or the number of interactions with their team members, thus lowering the likelihood or incidences for intragroup conflict to occur.

\section{Limitations and Future Research Directions}

Since this study is cross-sectional in nature, we cannot conclude causal relationships among the variables studied. Nonetheless, the use of advanced statistical techniques, such as structural equation modeling, in this study provides a helpful initial examination of the possible causal structure of relationships underlying goal interdependence, subgroup formation, and intragroup conflict 
variables. Future research should consider other study designs, such as experimental and time-series designs, which could help us further unpack the causal linkages among these variables.

Given that the participants worked in teams that were distributed across various sections of the same course, it was also possible for class-specific effects to have influenced the findings. As such, the conclusions from this research should be interpreted with caution, and that future investigations should take into account potential multilevel issues with clustered samples, and to use multilevel modeling, such as hierarchical linear modeling, to account for such effects.

Another key limitation of this research relates to the use of selfreported data. Self-reported data are subject to biases; however, past research has found that the use of self-reported data may not be as problematic as expected (Crampton \& Wagner, 1994; Specter, 1992). Future investigations are encouraged to use other forms of data, such as behavioral observations or other-reported scores, to overcome self-report biases or recall issues. The use of student teams in this study may also have limited the relevance and generalizability of the findings, thus pointing to the need for future research using actual or realistic team samples in organizational settings.

As data for all measures were collected from the same source, common method variance could also bias the study conclusions. However, given the findings from the confirmatory factor analyses conducted, the conclusion that a six-factor model fits the data best suggests that common method variance is unlikely to be an issue in this case (Podsakoff, MacKenzie, Lee, \& Podsakoff, 2003). Nevertheless, future research should use different data sources and methods to limit the possibility of common method variance as an alternative explanation for the results.

\section{Practical Implications}

Findings from this research suggest that managers or team leaders need to be aware of or better understand how members' perceptions of subgroups or cliques within their teams could contribute to higher levels of intragroup conflict, particularly if the team members perceive their goals as cooperatively linked. In these scenarios, it might be helpful for managers or team leaders to actively "disrupt" the subgroups by altering members' communication 
patterns or re-organizing tasks that reinforce those subgroup structures. Teams whose members perceive their goals as competitively linked, on the contrary, could be provided with specific training or developmental opportunities to enhance their communication, active listening and problem-solving skills, as one possible strategy for mitigating the direct negative effects of competitive goals on intragroup conflict.

\section{REFERENCES}

Bentler, P. M., \& Chou, C. H. (1987). "Practical Issues in Structural Modeling." Sociological Methods \& Research, 16: 78-117.

Bliese, P. D. (2000). "Within-Group Agreement, Non-Independence, and Reliability: Implications for Data Aggregation and Analysis. In K. J. Klein \& S. W. J. Kozlowski (Eds.), Multilevel Theory, Research, and Methods in Organizations: Foundations, Extensions, and New Directions. (pp. 349-381). San Francisco, CA: Jossey-Bass.

Bollen, K. A. (1989). Structural Equations with Latent Variables. New York: John Wiley.

Brewer, M. B. (1999). "The Psychology of Prejudice: Ingroup Love and Outgroup Hate?” Journal of Social Issues, 55(3): 429-444.

Byrne, D. E. (1971). The Attraction Paradigm (Vol. 11). New York: Academic Press.

Chen, N. Y., Tjosvold, D., Huang, X., \& Xu, D. (2011). "Newcomer Socialization in China: Effects of Team Values and Goal Interdependence." International Journal of Human Resource Management, 22(16): 3317-3337.

Chen, Y-F. N., Lu, J., Tjosvold, D., \& Lin, C. (2008). “Effects of Team Goal Interdependence on Newcomer Socialization: An Experiment in China." Journal of Applied Social Psychology, 38(1): 198-214.

Chen, Y-F. N., Tjosvold, D., \& Wu, P. G. (2008). "Effects of Relationship Values and Goal Interdependence on Guanxi between Foreign Managers and Chinese Employees." Journal of Applied Social Psychology, 38(10): 2440-2468. 
Chen, G., \& Tjosvold, D. (2012). "Shared Rewards and Goal Interdependence for Psychological Safety among Departments in China." Asia Pacific Journal of Management, 29(2): 433-452.

Cohen, G. S., \& Bailey, D. E. (1997). "What Makes Teams Work: Group Effectiveness Research from the Shop Floor to the Executive Suite." Journal of Management, 23(3): 239-290.

Crampton, S. M., \& Wagner, J. A., III. (1994). “Percept-Percept Inflation in Microorganizational Research: An Investigation of Prevalence and Effect." Journal of Applied Psychology, 79: 67-76.

Cronin, M. A., Bezrukova, K., Weingart, L. R., \& Tinsley, C. H. (2011). "Subgroups within a Team: The Role of Cognitive and Affective Integration." Journal of Organizational Behavior, 32(6): 831-849.

De Dreu, C. K. W., \& Weingart, L. R. (2003). “Task versus Relationship Conflict, Team Performance, and Team Member Satisfaction: A Meta-Analysis." Journal of Applied Psychology, 88(4): 741-749.

De Wit, F. R. C., Greer, L. L., \& Jehn, K. A. (2012). "The Paradox of Intragroup Conflict: A Meta-Analysis." Journal of Applied Psychology, 97(2): 360-390.

Deutsch, M. (1949). "A Theory of Co-operation and Competition." Human Relations, 2(2): 129-152.

Deutsch, M. (1973). The Resolution of Conflict: Constructive and Destructive Processes. New Haven, CT: Yale University Press.

Eisenhardt, K. M., \& Bourgeois, L. J. (1988). "Politics of Strategic Decision Making in High-Velocity Environments: Toward a Midrange Theory." Academy of Management Journal, 31(4): 737 770.

George, J. M., \& Bettenhausen, K. (1990). “Understanding Prosocial Behavior, Sales Performance, and Turnover: A Group-Level Analysis in a Service Context." Journal of Applied Psychology, 75(6): 698-709.

Griffith, J. A., Connelly, S., \& Thiel, C. E. (2014). "Emotion Regulation and Intragroup Conflict: When More Distracted Minds Prevail." International Journal of Conflict Management, 25(2): 148-170. 
Homan, A. C. \& Greer, L. L. (2007). "Demographic Faultlines and Subgroup Perception: The Positive Effects of Diversity Beliefs." Unpublished manuscript.

James, L. R., Demaree, R. G., \& Wolf, G. (1984). "Estimating WithinGroup Interrater Reliability with and without Response Bias." Journal of Applied Psychology, 69: 85-98.

James, L. R., Demaree, R. G., \& Wolf, G. (1993). "Rwg: An Assessment of Within-Group Interrater Agreement." Journal of Applied Psychology, 78: 306-309.

Jehn, K. A. (1994). "Enhancing Effectiveness: An Investigation of Advantages and Disadvantages of Value-Based Intragroup Conflict." International Journal of Conflict Management, 5: 223228.

Jehn, K. A. (1995). "A Multimethod Examination of the Benefits and Detriments of Intragroup Conflict." Administrative Science Quarterly, 40(2): 256-282.

Jehn, K. A. (1997). "A Qualitative Analysis of Conflict Types and Dimensions in Organizational Groups." Administrative Science Quarterly, 42(3): 530-557.

Jehn, K. A., \& Bendersky, C. (2003). "Intragroup Conflict in Organizations: A Contingency Perspective on the Conflict-Outcome Relationship." In B. Staw (Ed.), Research in Organizational Behavior, 25: 187-242.

Jehn, K. A., \& Bezrukova, K. (2010). "The Faultline Activation Process and the Effects of Activated Faultlines on Coalition Formation, Conflict , and Group Outcomes." Organizational Behavior and Human Decision Processes, 112(1): 24-42.

Jehn, K. A., Greer, L. L., \& Rupert, J. (2008). "Diversity, Conflict and Their Consequences." In A. P. Brief (Ed.), Diversity at Work (pp. 127-174). Cambridge, UK: Cambridge University Press.

Jehn, K. A., \& Mannix, E. A. (2001). “The Dynamic Nature of Conflict: A Longitudinal Study of Intragroup Conflict and Group Performance." Academy of Management Journal, 44(2): 238251. 
Johnson, D. W. (2003). "Social Interdependence: Interrelationships Among Theory, Research, and Practice." American Psychologist, 58(11): 934-945.

Johnson, D. W., \& Johnson, R. T. (2005). "New Developments in Social Interdependence Theory." Genetic, Social \& General Psychology Monographs, 131(4): 285-358.

Johnson, D. W., Maruyama, G., Johnson, R. T., Nelson, D., \& Skon, S. (1981). "Effects of Cooperative, Competitive, and Individualistic Goal Structures on Achievement: A Meta-Analysis." Psychological Bulletin, 89: 47-62.

Kozlowski, S. W. J., \& Bell, B. S. (2003). "Work Groups and Teams in Organizations." In W. C. Borman, D. R. Ilgen, \& R. J. Klimoski (Eds.), Handbook of Psychology: Industrial and Organizational Psychology (Vol. 12, pp. 333-375). New York: Wiley.

Lu, S. C. H., \& Tjosvold, D. (2013). “Socialization Tactics: Antecedents for Goal Interdependence and Newcomer Adjustment and Retention." Journal of Vocational Behavior, 83(3): 245-254.

Lu, J.-F., Tjosvold, D., \& Shi, K. (2010). "Team Training in China: Testing and Applying the Theory of Cooperation and Competition." Journal of Applied Social Psychology, 40(1): 101-134.

Mathieu, J., Maynard, M. T., Rapp, T., \& Gilson, L. (2008). “Team Effectiveness 1997-2007: A Review of Recent Advancements and A Glimpse Into the Future." Journal of Management, 34(3): 410476.

Medina, F., Munduate, L., \& Guerra, J. (2008). "Power and Conflict in Cooperative and Competitive Contexts." European Journal of Work and Organizational Psychology, 17(3): 349-362.

Murnighan, J. K., \& Brass, D. J. 1991. "Intraorganizational Coalitions: Research on Negotiation in Organizations." In M. H. Bazerman, R. J. Lewicki, \& B. H. Sheppard (Eds.), Handbook of Negotiation Research (Vol. 3, pp. 283-306). Greenwich, CT: JAI Press.

Muthén, L. K., \& Muthén, B. O. (1998-2012). Mplus User's Guide (7th ed.). Los Angeles, CA: Muthén \& Muthén.

Nunnally, J. C. (1967). Psychometric Theory. New York: McGraw-Hill. 
Podsakoff, P. M., Mackenzie, S. B., Lee, J.-Y., \& Podsakoff, N. P. (2003). "Common Method Biases in Behavioral Research: A Critical Review of the Literature and Recommended Remedies." Journal of Applied Psychology, 88(5): 879-903.

Polzer, J. T., Mannix, E. A., \& Neale, M. A. (1998). "Interest Alignment and Coalitions in Multiparty Negotiation. Academy of Management Journal, 41: 42-54.

Puck, J., \& Pregernig, U. (2014). "The Effect of Task Conflict and Cooperation on Performance of Teams: Are the Results Similar for Different Task Types?" European Management Journal, 32(6): 870-878.

Rispens, S., Greer, L., Jehn, K. A., \& Thatcher, S. M. B. (2011). “Not So Bad after All: How Relational Closeness Buffers the Association Between Relationship Conflict and Helpful and Deviant Group Behaviors." Negotiation and Conflict Management Research, 4(4): 277-296.

Shaw, J. D., Zhu, J., Duffy, M. K., Scott, K. L., Shih, H.-A., \& Susanto, E. (2011). "A Contingency Model of Conflict and Team Effectiveness." Journal of Applied Psychology, 96(2): 391-400.

Snijders, T., \& Bosker, R. (1999). Multilevel Analysis: An Introduction to Basic and Advanced Multilevel Modeling. Thousand Oaks, CA: Sage Publications.

Spector, P. E. (1992). "A Consideration of the Validity and Meaning of Self-Report Measures of Job Conditions." In C. L. Cooper, \& I. T. Robertson (Eds.), International Review of Industrial and Organizational Psychology (pp. 123-274). Rochester, NY: Wiley.

Tajfel, H., \& Turner, J. C. (1986). "The Social Identity Theory of Intergroup Behavior." In S. Worchel \& W. G. Austin (Eds.), Psychology of Intergroup Relations (pp. 7-24). Chicago, IL: Nelson-Hall.

Tekleab, A. G., Quigley, N. R., \& Tesluk, P. E. (2009). “A Longitudinal Study of Team Conflict, Conflict Management, Cohesion, and Team Effectiveness." Group \& Organization Management, 34(2): 170-205.

Tjosvold, D. (1986). "The Dynamics of Interdependence in Organizations." Human Relations, 39(6): 517-540. 
Tjosvold, D. (1990). "Flight Crew Collaboration to Manage Safety Risks." Group \& Organization Studies, 15(2): 177-191.

Tjosvold, D. (1998). "Cooperative and Competitive Goal Approach to Conflict: Accomplishments and Challenges." Applied Psychology: An International Review, 47(3): 285-313.

Tjosvold, D. (2002). "Managing Anger for Teamwork in Hong Kong: Goal Interdependence and Open-Mindedness." Asian Journal of Social Psychology, 5(2): 107-123.

Tjosvold, D. (2008). "The Conflict-Positive Organization: It Depends Upon Us." Journal of Organizational Behavior, 19(1): 19-28.

Tjosvold, D., Peng, A., Chen, Y., \& Su, F. (2008). "Business and Government Interdependence in China: Cooperative Goals to Develop Industries and the Marketplace." Asia Pacific Journal Of Management, 25(2): 225-249.

Tjosvold, D., Tang, M. L., \& West, M. (2004). "Reflexivity for Team Innovation in China: The Contribution of Goal Interdependence." Group \& Organization Management, 29(5): 540-559.

Tjosvold, D., \& Yu, Z. Y. (2004). "Goal Interdependence and Applying Abilities for Team In-Role and Extra-Role Performance in China." Group Dynamics: Theory, Research, and Practice, 8: 98-111.

Tjosvold, D., Yu, Z. Y., \& Hui, C. (2004). "Team Learning From Mistakes: The Contribution of Cooperative Goals and Problem Solving." Journal of Management Studies, 41: 1223-1245.

Tjosvold, D., Wong, A., Nibler, R., \& Pounder, J. S. (2002). “Teamwork and Controversy in Undergraduate Management Courses in Hong Kong: Can the Method Reinforce the Message?" Swiss Journal of Psychology, 61(3): 131-138.

Van Knippenberg, D., \& Schippers, M. C. (2007). "Work Group Diversity." Annual Review of Psychology, 58(1): 515-541.

Wong, A., Tjosvold, D., \& Liu, C. (2009). "Cross-Functional Team Organizational Citizenship Behavior in China: Shared Vision and Goal Interdependence Among Departments." Journal of Applied Social Psychology, 39(12): 2879-2909. 
Zellmer-Bruhn, M. E., Maloney, M. M., Bhappu, A. D., \& Salvador, R. (2008). "When and How Do Differences Matter? An Exploration of Perceived Similarity in Teams." Organizational Behavior and Human Decision Processes, 107(1): 41-59. 